\title{
The Impact of Smoking on Urologic Outcomes
}

\author{
Tom Feng ${ }^{1}$, Devin Patel ${ }^{1}$, Dhruv Khullar ${ }^{2}$, Mark Vogel ${ }^{1}$, John Maa ${ }^{3}$ \\ ${ }^{1}$ Division of Urology, Department of Surgery, Cedars Sinai Medical Center \\ ${ }^{2}$ Department of Medicine, Massachusetts General Hospital and Harvard Medical School \\ ${ }^{3}$ Chair, University of California Office of the President Tobacco Related Disease Research Program
}

\begin{abstract}
:
Purpose: Cigarette smoking is the leading preventable cause of morbidity and mortality in the US and worldwide. The surgical literature demonstrates that active tobacco smoking is a major risk factor for perioperative morbidity and complications, and that preoperative smoking cessation is effective in reducing these associated risks. However, few studies have examined the dual effects of smoking on the etiology and treatment of urologic conditions, and perioperative complications following urologic procedures. The goal of this review is to highlight the scientific data regarding the impact of smoking on urologic conditions and outcomes, and to suggest ways that urologists can promote smoking cessation with their patients, and lead efforts to emphasize preoperative smoking cessation.
\end{abstract}

Materials and Methods: The words "smoking and urology" or "tobacco and urology" were used as search terms in PubMed (for the years 1950-2014) to identify all articles that included at least one of these terms or phrases. All of the articles were evaluated, and the 67 key references included in this review.

Results: There is strong evidence that smoking is associated with higher incidence rates of malignant and benign urological conditions, an increased risk of perioperative complications, and inferior long term outcomes. The increased risks of developing bladder and kidney cancer are well recognized in smokers, and an adverse impact on postoperative outcomes in the treatment of testicular and prostate cancer have been described. Smoking also is implicated in the pathogenesis of benign conditions such as nephrolithiasis, lower urinary tract symptoms and erectile dysfunction, and adversely impacts renal transplant outcomes. Smoking portends worse outcomes after medical and surgical management of different urological conditions, and evidence suggests that urologists can increase preoperative smoking cessation rates through a combination of counseling and pharmacologic therapy.

Conclusions: Further research is needed to reduce the impact of smoking on perioperative urologic complications, and to characterize the related costs to the healthcare system. Urologists should encourage preoperative smoking cessation as part of their clinical practice to reduce perioperative morbidity and worsened outcomes associated with active smoking.

Keywords: tobacco control, smoking cessation, perioperative, renal cell carcinoma, bladder carcinoma

\section{INTRODUCTION}

Cigarette smoking is the leading preventable cause of morbidity and mortality worldwide. In the US, smoking is attributable for at least 15 malignancies and a third of all annual cancer deaths [1]. One in five deaths in the US is due to tobacco use, translating to nearly half a million deaths annually [1]. Despite intense public health efforts, an estimated 44 million Americans continue to smoke and the prevalence continues to rise [1]. The CDC has estimated that the economic costs of smoking total more than $\$ 300$ billion a year, including $\$ 170$ billion in direct medical care and more than $\$ 156$ billion in lost productivity due to premature death and secondhand smoke exposure.

Smoking has long been identified as a risk factor for chronic disease. Growing evidence suggests it is also an independent risk factor for surgery by increasing the risk of perioperative cardiovascular, pulmonary, and wound and bone healing complications, that translate into lengthier hospital stays, higher rates of ICU utilization, greater reoperation rates, higher overall costs and increased mortality [2]. In a retrospective cohort study of data from the American College of Surgeons National Surgical Quality Improvement Program (NSQIP), 82,304 current smokers were propensity matched with 82,304 never-smoker controls [3]. Smokers experienced an increase in a wide range of adverse events following surgery including cardiac arrest, myocardial infarction, stroke, superficial and deep wound 
infections, sepsis, and shock, and were 1.38 times more likely to die following surgery than nonsmokers. A number of studies indicate that patients should be advised to stop smoking before elective surgery to minimize the risk of complications and maximize long-term benefits of treatment $[2,3]$.

In the field of urology, smoking was identified as a causative agent for bladder cancer in 1990, kidney cancer in 2004, and most recently, male sexual dysfunction in 2014 [1]. However, the relationship to disease progression, treatment response and treatment toxicity has not been as well characterized. Specifically, the effects of smoking on perioperative morbidity following urological procedures are less well defined. In this review, we sought to highlight the existing scientific data regarding the impact of smoking on urological outcomes, and suggest ways that urologists can promote preoperative smoking cessation.

\section{MeTHODS}

To assess the impact of smoking in urology, the words "smoking and urology" or "tobacco and urology" were used as search terms in PubMed (for the years 1950-2015) to identify all articles that included at least one of these terms or phrases by two independent reviewers (TF and DP). The list of references from the relevant articles and systematic reviews were evaluated for additional sources. Over 150 articles were evaluated, and the leading 67 references that illustrate the impact of smoking upon urologic conditions were included in this article. The manuscript was prepared in accordance with the principles of the Helsinki Declaration.

\section{RESULTS}

\subsection{How Smoking Contributes to Urologic Diseases and Perioperative Complications}

The increased risk that smoking poses in urology relates to both the long-term consequences of tobacco use (i.e. chronic obstructive pulmonary disease, coronary artery disease and neoplasia) and the acute toxic effects of recent smoke exposure. The excess morbidity results from: 1) the pathogenic properties of tobacco in contributing to the underlying urologic malignancy (Table 1) or benign urologic condition (Table 2);2) perioperative anesthetic and medical complications attributable to smoking related co-morbidities; 3) unfavorable impact of smoking on long term outcomes of postoperative adjuvant or medical therapies.

Table1. The impact of smoking on urologic cancers

\begin{tabular}{|l|l|}
\hline Disease & Smoking-related risks and complications \\
\hline Bladder & Current smoking increases risk by as much as 4-fold \\
Cancer & Smokers present at younger ages and with higher T stage tumors \\
\hline Kidney & Current smokers have 40\% increased risk of renal cell carcinoma \\
Cancer & Risk increases with smoking intensity/ duration, decreases with cessation \\
\hline Prostate & Heavy smokers are 2.6 times as likely to be diagnosed with prostate cancer, and have an $89 \%$ \\
Cancer & increased risk of high grade cancer as compared to light or never smokers. \\
& Smokers have poorer erectile function after prostatectomy or radiation therapy \\
\hline Testicular & Unclear association with smoking \\
Cancer & Further studies needed to delineate risk \\
\hline
\end{tabular}

Table2. The impact of smoking on benign urologic conditions

\begin{tabular}{|l|l|}
\hline Disease & Smoking-related risks and complications \\
\hline Erectile Dysfunction & $\begin{array}{l}\text { Relative risk of ED = 1.31 for every 10 pack-years; smokers have poorer response } \\
\text { to phosphodiesterase inhibitor and reduced physiologic and self-reported sexual } \\
\text { health }\end{array}$ \\
\hline Infertility & $\begin{array}{l}\text { Smokers have decreased semen volume, sperm number, and percentage of motile } \\
\text { sperm. Smokers have 3-fold higher rate of treatment failure with in vitro } \\
\text { fertilization }\end{array}$ \\
\hline $\begin{array}{l}\text { Chronic Renal Disease } \\
\text { and Transplantation }\end{array}$ & $\begin{array}{l}\text { Current smoking associated with greater GFR decline. Smoking associated with } \\
\text { increased risk of allograft loss and death after transplantation }\end{array}$ \\
\hline Nephrolithiasis & $\begin{array}{l}\text { Smoking may be stronger risk factor of calcium oxalate stone formation than HTN, } \\
\text { HLD, or BMI. Smoking confers negative impact on spontaneous passage of some } \\
\text { kidney stones }\end{array}$ \\
\hline $\begin{array}{l}\text { Lower Urinary Tract } \\
\text { Symptoms }\end{array}$ & $\begin{array}{l}\text { Smoking increases risk of mesh erosion after vaginal sling procedures. Smoking } \\
\text { increases morbidity after TURP for BPH }\end{array}$ \\
\hline
\end{tabular}


Abbreviations: ED, erectile dysfunction; GFR, glomerular filtration rate; HTN, hypertension; HLD, hyperlipidemia; BMI, body mass index; TURP, transurethral resection of the prostate; $B P H$, benign prostatic hypertrophy.

Most tobacco products are made from the species Nicotiana tabacum, which contains approximately 4,000 chemical compounds, at least 55 of which are carcinogenic. Cigarette smoke has a number of toxic effects, including impaired immune function, free radical release, cellular damage, and thrombogenesis [4]. These combined effects on the microvasculature are exacerbated by carbon monoxide, and result in the detrimental delivery of essential oxygen, nutrients, growth factors and immune cells thereby contributing to tissue hypoxia and delayed wound healing. Tobacco also stimulates a stress response mediated by enhanced fibroblast activity resulting in decreased cell migration and increased cell adhesion [4]. This results in is inappropriate connective tissue deposition at the surgical site and delayed wound healing.

\subsection{The Impact of Smoking on Urological Outcomes}

\subsubsection{Bladder Cancer}

Bladder cancer is the second most common malignancy of the genitourinary system, and also the second most common tobacco-related malignancy following lung cancer. Cigarette smoking has been repeatedly shown to be the leading cause of bladder cancer. Cigarette smoke contains many known bladder carcinogens including B-naphthylamine, polycystic aromatic hydrocarbons, and other aromatic amines [4]. These substances are renally excreted, concentrate within the bladder, and directly affect the urothelial tissue. In addition to the mechanisms described earlier, the carcinogens in tobacco exert an oncogenic effect by inducing p53 mutations, rendering chromosomal abnormalities, and suppressing immune function

The high prevalence of smoking among patients undergoing surgery for bladder cancer has resulted in numerous studies investigating the role of smoking in carcinogenesis, cancer progression, postoperative complications, and treatment response. Recent studies indicate that the populationattributable risk of bladder cancer for tobacco smoking as 50\% in men and 52\% in women[5]. Current smoking increases the risk of developing bladder cancer by as much as fourfold [5]. The intensity and duration of smoking also confers increased risk of cancer, whereas smoking cessation reduces but does not eliminate this risk [6]. The immediate decrease in risk of bladder cancer was $30 \%$ after 1-4 years of abstinence and over $60 \%$ after 25 years [6]. A case comparison study of over 1000 patients with bladder cancer showed that current smokers were four years younger, and had larger and higher $\mathrm{T}$ stage tumors compared with never smokers. In addition, muscle invasive disease was more prevalent in current and former smokers compared to nonsmokers [7]. Furthermore, patients with a heavy smoking history are more likely to have clinically advanced disease at presentation.

One study investigating robotic cystectomy showed smoking as a risk factor for the development of high grade complications, defined as those requiring invasive management, repeat surgery or resulting in lasting disability [8]. In both superficial and invasive disease, smoking intensity and duration shows a dose-responsive negative effect on tumor stage, regional metastasis and disease recurrence after surgery $[9,10]$.

Following surgical treatment for bladder cancer, patients diagnosed at earlier stages are more likely to continue smoking; however, continued and prolonged smoking exposure is negatively associated with disease progression $[9,11]$. Smoking also negatively impacts postoperative adjuvant bladder cancer treatments. During chemotherapy, smoking can exacerbate drug side effects, further impair immune function, increase the incidence of infection, exacerbate treatment related cachexia, and induce hepatic enzymes to alter metabolism rates [12]. Smoking is a risk factor for cisplatin nephrotoxicity [13]. Smokers are more likely to both fail initial Bacillus Calmette Guerin (BCG) therapy, and recur after treatment [9].

\subsubsection{Kidney Cancer}

Cigarette smoking has now been established by the US Surgeon General as an established causal riskfactor for developing renal cell cancer. A review of the various environmental risk factors revealed that the strongest association is between smoking and the development of kidney cancers involving the renal parenchyma and renal pelvis/ureter [14]. Studies have shown a clear dose-response correlation, and an observed benefit of smoking cessation on risk reduction. A multicenter, population based case control study of over 1,730 smokers and 2,300 control patients showed that current smokers have a $40 \%$ increase in risk in renal cell carcinoma $(\mathrm{RR}=1.4)$ [15]. The risk also increased 
with number of cigarettes smoked and duration of smoking. Furthermore, former smokers who abstained from smoking for more than 15 years experienced a reduction in risk of about $15-25 \%$ relative to current smokers.

Smoking also affects outcomes related to cancer specific mortality. Smokers were found to have more aggressive disease and more advanced tumors at presentation. Smoking was associated significantly with tumor multifocality, higher pathologic tumor classification, an increased risk of bulky lymph node disease, and the presence of distant metastasis[16]. The study also showed a poorer cancerspecific survival after nephrectomy for smokers [16].

Furthermore, smoking is a renal toxin, predisposing to postoperative acute kidney injury (AKI) and chronic renal failure (CRF). Studies show that chronic nicotine exposure leads to up-regulation of renal oxidative stress pathways with exacerbation of ischemia-reperfusion induced free-radical generation and AKI [17]. Indeed, studies show that the incidence of AKI is higher among smokers following radical nephrectomy with thrombectomy, major vascular surgery, and intravenous contrast exposure[18]. After radical or partial nephrectomy, smoking is a risk factor for developing CRF. Following RCC surgery, smoking cessation may be equally important as surgical technique in preserving long-term glomerular function, as a serum creatinine rising above $2.0 \mathrm{mg} / \mathrm{dL}$ was more common in smokers compared to non-smokers (OR 5.29; 95\% CI 2.58-10.87). This increased risk for a serum creatinine rise is similar for smokers over non-smokers as compared to those undergoing radical nephrectomy over renal sparing surgery (OR 3.08; 95\% CI 1.64-5.78)[19].

In addition, smoking may adversely affect medical treatment of metastatic renal cell carcinoma. One study showed that active smoking negatively affected the progression free survival and overall survival of patients with metastatic RCC undergoing treatment with sunitinib [20]. Smokers are at higher risk of having abnormal baseline pulmonary function tests, thereby potentially excluding them from IL-2 therapy. Thus, the benefit of smoking cessation in kidney cancer therapy extends beyond reducing cancer risk and progression, but also to extending the effectiveness of adjuvant treatment.

\subsubsection{Prostate Cancer}

The established risk factors for prostate cancer include increasing age, African American ethnicity, and positive family history. Only recently has smoking been linked to increased prostate cancer risk. Plaskon et al compared 753 male smokers ages 40-64 diagnosed with prostate cancer with agematched controls, and demonstrated current smokers to have an increased risk $(\mathrm{OR}=1.4)$ relative to nonsmokers [21]. A dose-response relationship was also noted between duration of smoking and prostate cancer risk and aggressiveness of disease. An earlier age at which men first started smoking was also a strong risk factor for aggressive disease.

A proposed mechanism of tobacco in prostate cancer genesis and progression include the increased exposure to carcinogenic compounds in cigarettes, such as polycyclic aromatic hydrocarbons, heterocyclic aromatic amines, nitrosamines, and cadmium [22]. Smoking is also associated with an increase in bioavailable serum androgens and decrease in estradiol [23]. Testosterone and its potent metabolite DHT are necessary for normal prostate cell development and proliferation and conversely, estrogens act on the hypothalamus pituitary axis to suppress androgen production. Thus the changes in hormone levels associated with smoking may contribute to the development and progression of prostate cancer.

Smoking is associated with adverse pathologic features and a higher risk of biochemical recurrence in men undergoing radical prostatectomy. Among patients undergoing radical prostatectomy, cigarette smoking was associated with an increased risk of metastasis and higher risk of biochemical recurrence, castrate resistant prostate cancer, and overall mortality [24]. Smoking also negatively impacts patients undergoing curative external beam radiation therapy for localized disease. Pickles et al demonstrated that current smokers presented with higher risk cancers, and smoking was an independent risk factor for poorer outcome following radiation therapy [25]. In addition, smoking adversely impacts erectile function recovery after radical prostatectomy [26]. Smoking was the strongest predictor of bladder neck contracture when compared to coronary artery disease, hypertension, and diabetes [26]. Smoking has also been associated with a negative impact upon erectile function after external beam pelvic irradiation for prostate cancer. Goldstein et al showed a higher incidence of smoking in men who lost potency after radiation therapy [27]. 


\subsubsection{Testicular Cancer}

Unlike the other urological malignancies, the link between testicular cancer and smoking is less clearly defined. The UK Testicular Cancer Study Group evaluated smoking exposure in a case-control study of 794 men with testicular cancer and did not find a significantly increased risk with cigarette smoking [28]. In contrast, a recent study from Canada did demonstrate an increased risk of testicular cancer in men with greater than 12 pack year history [29]. Of note, however, they did not notice any association with age of initiation of smoking nor reduction of risk with smoking cessation. Further studies are needed to definitely delineate the effect of smoking and testicular cancer.

There is stronger evidence that smoking impacts outcomes after testicular cancer surgery and adjuvant treatment. Smoking-induced free radical damage and vascular injury increase the risk of bleomycininduced pulmonary toxicity and Raynaud's phenomenon after adjuvant therapy for testicular cancer [30]. The rates of major complications in testicular cancer survivors, including secondary malignancy, early cardiovascular disease, depression, anxiety and sexual function inventory scores are all negatively affected by smoking $[31,32]$. The effect of smoking on fertility following orchiectomy has not been studied directly, but smoking alters seminal fluid to introduce free radicals, deplete antioxidants and increase leukocyte content [33]. This contributes to increased oxidative species, which are known to harm sperm during cryopreservation.

\subsubsection{Testicular Dysfunction}

The evidence for the effect of smoking on male fertility is evolving. Current evidence shows a negative influence that begins before birth, continues into adulthood, and alters assisted-reproductive outcomes. In utero smoke exposure is associated with higher risk for bilateral cryptorchidism and reduced adult sperm quality, count and testicular size [34]. Adult male smokers have decreased semen volume, sperm number and percentage of motile forms [33]. Sperm samples from smokers in both general and infertility clinic populations have shown higher genetic damage, abnormal morphology, altered meiosis and reduced acrosin activity [35]. Among male smokers, these effects translate into a three-fold higher rate of treatment failure with both in vitro fertilization and intra-cytoplasmic sperm injection [36].

Smoking compounds the effect of a varicocele on infertility and may impact treatment response. Among patients with a varicocele, the incidence of oligospermia is tenfold higher in smokers. A study of infertile patients with varicoceles found that seminal cadmium levels rose with smoke exposure, and predicted testicular atrophy and poor response to varicocelectomy [37]. Smoking cessation should be universally recommended in patients presenting with infertility. In addition to reducing maternal second-hand exposure, tobacco abstinence for as little as 3 months results in improved semen parameters [38].

\subsubsection{Erectile Dysfunction}

Independent of other factors, there is a 30\% higher risk for erectile dysfunction (ED) with each 10 pack-years smoked [1,39]. Unlike other risk factors for ED, the magnitude of the association between smoking and ED decreases with older age, suggesting a stronger relationship in young male smokers [39]. Smoking-induced arterial atherosclerosis is the main culprit in the higher prevalence of early onset ED, and a poorer response to treatment [40]. Tobacco-mediated hypoxia induces fibrosis and resultant venous leakage, a condition associated with high treatment refractoriness [40]. Smoking directly impairs the main mechanisms that maintain cavernosal health, endothelial nitric oxide synthase, VEGF signaling and tissue oxygen pressure [41]. Because of these changes, active smoking is a risk factor for poor response to phosphodiesterase-5 inhibitors [42]. Following intracavernous PgE1 injection, male smokers, independent of baseline potency and co-existing arterial disease, show worse erectile response and reduced flow parameters when compared to non-smoking counterparts [43]. Smoking cessation, even with nicotine replacement, can significantly enhance physiological and self-reported indices of sexual health in long-term male smokers [44].

\subsubsection{Nephrolithiasis}

Cigarette smoking has also been implicated as a risk factor for forming calcium urolithiasis [45]. In fact, smoking may be a stronger risk factor of calcium oxalate stone formation than hypertension, hypercholesterolemia, or BMI [46]. Scott et al also demonstrated that increased serum cadmium 
levels, a known toxin of cigarettes, may be a risk factor for urinary tract stone formation as $40 \%$ of the group with high cadmium levels had kidney stones compared to $3.5 \%$ in the general population [47]. Furthermore, smoking seems to also confer a negative impact on spontaneous passage of some kidney stones. Though total stone passage rates were similar in smoking and nonsmoking groups, the passage rate in patients with stone diameters greater than $4 \mathrm{~mm}$ was lower in smokers [48].

\subsubsection{Lower Urinary Tract Symptoms}

Lower urinary tract symptoms (LUTS) represent a common urological complaint. This collection of urinary symptoms often present in older men with benign prostatic hyperplasia but may be seen in other urological disorders. One study showed a positive correlation with smoking and prevalence of lower urinary tract symptoms, and also emphasized the importance of smoking cessation as the risk of LUTS was decreased with long term abstinence [49]. Other studies have demonstrated a positive association between smoking and symptoms such as urgency, nocturia, and female urinary incontinence [50]. The incidence of female stress incontinence is higher in current smokers than former smokers, and the intensity and duration of cigarette consumption are associated with higher risk for stress incontinence [51].

Smoking also appears to negatively impact outcomes of surgeries related to LUTS. Current smoking status has been shown as a risk factor for mesh erosion for those undergoing vaginal sling procedures for urinary incontinence [52]. Former and current smoking status has been shown to increase morbidity after transurethral resection of the prostate for $\mathrm{BPH}$, by increasing the risk of large scale fluid absorption (greater than 1L) with former and current smoking status. [53] The outcome following urethroplasty in smokers is poor, and includes a high rate of stricture reformation [54].

\subsubsection{Chronic Renal Failure and Kidney Transplant Surgery}

The kidney is susceptible to the pathogenic effects of tobacco use. Recent data from experimental studies indicate that smoking is a risk factor for renal function deterioration. One study demonstrated a 4.3 fold greater rate of GFR decline observed in active vs nonactive smokers. The rate of GFR decline was also independently associated with heavy smoking [55]. Another study showed that second-hand smoking was independently associated with nephrotic range proteinuria and thus plays a role in chronic kidney disease progression [56].

The effects of smoking on kidney transplantation have been studied extensively. Smoking, both by donors and by recipients, has a negative effect on transplant outcomes including an increased risk of allograft loss and death [57] resulting from fibrous intimal thickening of small arteries. Patients who were smokers at the time of pretransplant evaluation had kidney graft survival of $84 \%, 65 \%$, and $48 \%$ at 1,5 , and 10 years, respectively, compared with graft survival in nonsmokers of $88 \%, 78 \%$, and $62 \%$ [58]. They also reported that $90 \%$ of recipients who were smokers continued to smoke. For those who quit prior to receiving a transplant, graft survival was higher. In addition, smoking by kidney donors also negatively affects donor and recipient renal function following living donor nephrectomy [59]. Donors who actively smoke or have a past history of tobacco use have a larger percent increase in creatinine at one year following donation compared to donors who have never smoked. Recipients of smoker's organs are also at a greater risk of extended intensive care stays and greater need for ventilation. Furthermore, smoking by kidney transplant recipients significantly increases the risk of cardiovascular events, renal fibrosis, rejection, and malignancy [60].

\subsubsection{Smoking Cessation: the "Teachable Moment" and Current Barriers}

The public has a low overall awareness of smoking's impact on urological conditions. Only 33.5\%, $25.2 \%$ and $24.2 \%$ of patients identified smoking as a risk factor for kidney cancer, bladder cancer, and erectile dysfunction, respectively, compared to $94.0 \%$ who identified it as a risk factor for lung cancer. This lack of awareness is most pronounced in ethnic minorities and current smokers. Hispanic and black patients were 2 to 3 times more likely than white patients, and smokers were twice as likely as nonsmokers, to be unaware of the association of smoking with kidney and bladder cancer [61]

A "teachable moment" is an event such as disease diagnosis or hospitalization that motivates a patient to change a risky health behavior, when they are particularly concerned about their health. The scheduling of elective surgery after the diagnosis of bladder cancer presents a powerful opportunity 
for urologists to encourage smoking cessation, as one study showed that smokers newly diagnosed with bladder cancer were almost five times more likely to quit than smokers in the general population. These patients cited their new diagnosis and the advice from urologists as the key reasons for cessation [62] Preoperative smoking cessation not only decrease perioperative morbidity, but also promotes permanent smoking cessation to enable the patient to benefit from a tobacco-free life longterm.

Despite the potential "teachable moment" that surgery presents for smoking cessation, urologists are currently not capitalizing on this opportunity (Table 3). More than half of urologists never discuss smoking cessation, and only one-fifth discuss smoking cessation with patients with bladder cancer, the malignancy with the strongest association with smoking [62]. Perhaps the current thinking of urologists needs to be reframed to promote the awareness of smoking and its association with urological diseases. Of urologists who never discuss smoking cessation, $40.7 \%$ believe that smoking cessation may not change the outcome of the disease, and $37.7 \%$ do not feel qualified to provide counseling [62]. Additionally, most urologists (93.7\%) have never had formal smoking cessation training [62]. Urologists who had some form of cessation training were more likely to provide counseling compared to those without training [62].

Table3. Smoking Cessation in Urology Patients - Barriers and Opportunities

\begin{tabular}{|l|l|}
\hline Barriers & Comment \\
\hline $\begin{array}{l}\text { Limited patient understanding of smoking's } \\
\text { contributions to urologic conditions }\end{array}$ & $\begin{array}{l}\text { Less than one-third of patients identify smoking as a risk } \\
\text { for kidney or bladder cancer, or erectile dysfunction. }\end{array}$ \\
\hline $\begin{array}{l}\text { Surgeons and urologists do not routinely } \\
\text { counsel patients to stop smoking }\end{array}$ & $\begin{array}{l}\text { Almost half of all surgeons do not routinely counsel } \\
\text { patients to stop smoking pre-op. Over half of urologists } \\
\text { never discuss smoking cessation; only one-fifth discuss } \\
\text { smoking with bladder cancer patients. }\end{array}$ \\
\hline $\begin{array}{l}\text { Urologists are not trained to provide smoking } \\
\text { cessation counseling }\end{array}$ & $\begin{array}{l}\text { Of urologists who never discuss smoking, 41\% believe } \\
\text { cessation may not change outcome, 38\% feel unqualified } \\
\text { to give counseling, and over 90\% never had formal } \\
\text { cessation training. }\end{array}$ \\
\hline $\begin{array}{l}\text { Opportunities "teachable moment" can motivate patients } \\
\text { to change risky health behaviors }\end{array}$ & $\begin{array}{l}\text { Smokers newly diagnosed with bladder cancer are almost } \\
\text { 5 times more likely to quit than smokers in the general } \\
\text { population. }\end{array}$ \\
\hline $\begin{array}{l}\text { Even brief counseling can increase cessation } \\
\text { rates }\end{array}$ & $\begin{array}{l}\text { A 5-min cessation intervention significantly increases 1- } \\
\text { year quit rates. Adding nicotine replacement further } \\
\text { increases quit rates. }\end{array}$ \\
\hline $\begin{array}{l}\text { Urologists can provide a number of simple, } \\
\text { evidence-based interventions to increase } \\
\text { cessation rates for their patients }\end{array}$ & $\begin{array}{l}\text { Effective interventions include motivational interviewing, } \\
\text { individual counseling, group counseling, telephone } \\
\text { hotlines, hiring cessation specialist in practice, and } \\
\text { offering nicotine replacement therapy. }\end{array}$ \\
\hline
\end{tabular}

\subsection{Effective Methods for Smoking Cessation}

Effective interventions that urologists can utilize to help patients to stop smoking include simple open dialog about the patient's motivation to quit, individual counseling, group counseling, and repeated personal contact. A novel smoking warning label to raise awareness of the deleterious effects of smoking on bladder cancer was shown to a cohort of 291 patients at urology and family practice clinics: $58.1 \%$ stated that it had changed their opinion on smoking and bladder cancer and $74.8 \%$ felt that this label would raise awareness of the hazards. [63] Moving beyond raising awareness are investigations of smoking cessation interventions. One study compared patients who were enrolled in either 1) a brief 5 minute smoking cessation intervention, 2) intervention plus nicotine replacement therapy, or 3) a control group [64]. They demonstrated the one year quit rate in the intervention group was $12.1 \%$ vs $2.6 \%$ in controls. The addition of nicotine replacement therapy increased the quit rate to $19.5 \%$. Patients enrolled in the brief smoking cessation intervention were also more willing to attempt to quit. This study demonstrates how urologists can successfully implement a smoking cessation program.

Finally, newer urine markers are being developed to help clinicians validate abstinence. Urinary nicotine levels will be elevated in both active smokers and those on nicotine replacement therapy. Urine concentration of the tobacco alkaloids anabasine and anatabine have been demonstrated to be 
useful biomarkers to distinguish active tobacco use from patients on nicotine replacement therapy [65]. With these new markers, clinicians can individualize counseling with their patients who are in cessation programs, and monitor patient compliance and success.

\section{DisCUSSION}

In this paper, we reviewed the literature on the impact of former and active smoking on urologic outcomes. Our findings indicate that smoking not only significantly increases the risk of cardiac, respiratory, and septic complications following surgery, but also increases the risk of developing both malignant and benign urological diseases. Importantly, smoking abstinence may avert these negative consequences, and one of the most powerful times to convince a smoker to quit is after the diagnosis of a smoking- related illness and before a related elective surgical procedure. However, specific to urology, there was no difference observed for 30-day morbidity or length of stay following urological surgery among smokers and nonsmokers [66, 67], which represents an important area for further research. Our review of the existing literature suggests that a deeper understanding and estimate of the economic costs of prolonged hospitalizations, readmissions, and complications after surgery related to active smoking is necessary. A partnership between urologists, tobacco control leaders, and policymakers could dramatically improve health outcomes.

\section{Conclusion}

Our findings indicate that smoking not only significantly increases the risk of cardiac, respiratory, and wound complications following surgery, but also increases the risk of developing for both malignant and benign urological diseases. Importantly, smoking abstinence may avert these negative consequences, and the scheduling of elective surgery presents a valuable opportunity to initiate smoking cessation interventions.

\section{ACKNOWLEDGEMENTS}

The authors would like to thank Pamela Derish MA for editorial assistance.

\section{REFERENCES}

[1] In The Health Consequences of Smoking-50 Years of Progress: A Report of the Surgeon General. 2014: Atlanta (GA).

[2] Khullar, D. and J. Maa, The impact of smoking on surgical outcomes. J Am Coll Surg, 2012. 215(3): p. 418-26.

[3] Turan, A., et al., Smoking and perioperative outcomes. Anesthesiology, 2011. 114(4): p. 837-46.

[4] In How Tobacco Smoke Causes Disease: The Biology and Behavioral Basis for SmokingAttributable Disease: A Report of the Surgeon General. 2010: Atlanta (GA).

[5] Freedman, N.D., et al., Association between smoking and risk of bladder cancer among men and women. JAMA, 2011. 306(7): p. 737-45.

[6] Brennan, P., et al., Cigarette smoking and bladder cancer in men: a pooled analysis of 11 casecontrol studies. Int J Cancer, 2000. 86(2): p. 289-94.

[7] van Roekel, E.H., et al., Smoking is associated with lower age, higher grade, higher stage, and larger size of malignant bladder tumors at diagnosis. Int J Cancer, 2013. 133(2): p. 446-54.

[8] Johar, R.S., et al., Complications after robot-assisted radical cystectomy: results from the International Robotic Cystectomy Consortium. Eur Urol, 2013. 64(1): p. 52-7.

[9] Rink, M., et al., Impact of smoking and smoking cessation on oncologic outcomes in primary non-muscle-invasive bladder cancer. Eur Urol, 2013. 63(4): p. 724-32.

[10] Rink, M., et al., Impact of smoking and smoking cessation on outcomes in bladder cancer patients treated with radical cystectomy. Eur Urol, 2013. 64(3): p. 456-64.

[11] Ostroff, J., et al., Cigarette smoking patterns in patients after treatment of bladder cancer. J Cancer Educ, 2000. 15(2): p. 86-90.

[12] Gritz, E.R., C. Dresler, and L. Sarna, Smoking, the missing drug interaction in clinical trials: ignoring the obvious. Cancer Epidemiol Biomarkers Prev, 2005. 14(10): p. 2287-93.

[13] Miller, R.P., et al., Mechanisms of Cisplatin nephrotoxicity. Toxins (Basel), 2010. 2(11): p. 2490-518. 
[14] Moore, L.E., R.T. Wilson, and S.L. Campleman, Lifestyle factors, exposures, genetic susceptibility, and renal cell cancer risk: a review. Cancer Invest, 2005. 23(3): p. 240-55.

[15] McLaughlin, J.K., et al., International renal-cell cancer study. I. Tobacco use. Int J Cancer, 1995. 60(2): p. 194-8.

[16] Kroeger, N., et al., Smoking negatively impacts renal cell carcinoma overall and cancer-specific survival. Cancer, 2012. 118(7): p. 1795-802.

[17] Arany, I., et al., Chronic nicotine exposure exacerbates acute renal ischemic injury. Am J Physiol Renal Physiol, 2011. 301(1): p. F125-33.

[18] Shin, S., et al., Risk factors for acute kidney injury after radical nephrectomy and inferior vena cava thrombectomy for renal cell carcinoma. J Vasc Surg, 2013. 58(4): p. 1021-7.

[19] Malcolm, J.B., et al., Comparison of rates and risk factors for developing chronic renal insufficiency, proteinuria and metabolic acidosis after radical or partial nephrectomy. BJU Int, 2009. 104(4): p. 476-81.

[20] Keizman, D., et al., Active smoking may negatively affect response rate, progression-free survival, and overall survival of patients with metastatic renal cell carcinoma treated with sunitinib. Oncologist, 2014. 19(1): p. 51-60.

[21] Plaskon, L.A., et al., Cigarette smoking and risk of prostate cancer in middle-aged men. Cancer Epidemiol Biomarkers Prev, 2003. 12(7): p. 604-9.

[22] Nock, N.L., et al., Polymorphisms in polycyclic aromatic hydrocarbon metabolism and conjugation genes, interactions with smoking and prostate cancer risk. Cancer Epidemiol Biomarkers Prev, 2006. 15(4): p. 756-61.

[23] Shiels, M.S., et al., Association of cigarette smoking, alcohol consumption, and physical activity with sex steroid hormone levels in US men. Cancer Causes Control, 2009. 20(6): p. 877-86.

[24] Moreira, D.M., et al., Cigarette smoking is associated with an increased risk of biochemical disease recurrence, metastasis, castration-resistant prostate cancer, and mortality after radical prostatectomy: results from the SEARCH database. Cancer, 2014. 120(2): p. 197-204.

[25] Pickles, T., et al., The effect of smoking on outcome following external radiation for localized prostate cancer. J Urol, 2004. 171(4): p. 1543-6.

[26] Borboroglu, P.G., et al., Risk factors for vesicourethral anastomotic stricture after radical prostatectomy. Urology, 2000. 56(1): p. 96-100.

[27] Goldstein, I., et al., Radiation-associated impotence. A clinical study of its mechanism. JAMA, 1984. 251(7): p. 903-10.

[28] Social, behavioural and medical factors in the aetiology of testicular cancer: results from the UK study. UK Testicular Cancer Study Group. Br J Cancer, 1994. 70(3): p. 513-20.

[29] Srivastava, A. and N. Kreiger, Cigarette smoking and testicular cancer. Cancer Epidemiol Biomarkers Prev, 2004. 13(1): p. 49-54.

[30] Chaudhary, U.B. and J.R. Haldas, Long-term complications of chemotherapy for germ cell tumours. Drugs, 2003. 63(15): p. 1565-77.

[31] Dahl, A.A., et al., Is the sexual function compromised in long-term testicular cancer survivors? Eur Urol, 2007. 52(5): p. 1438-47.

[32] Shinn, E.H., et al., Health behaviors and depressive symptoms in testicular cancer survivors. Urology, 2007. 69(4): p. 748-53.

[33] Zhang, Z.H., et al., Decline of semen quality and increase of leukocytes with cigarette smoking in infertile men. Iran J Reprod Med, 2013. 11(7): p. 589-96.

[34] Ravnborg, T.L., et al., Prenatal and adult exposures to smoking are associated with adverse effects on reproductive hormones, semen quality, final height and body mass index. Hum Reprod, 2011. 26(5): p. 1000-11.

[35] Pereira, C.S., et al., Smoking-induced chromosomal segregation anomalies identified by FISH analysis of sperm. Mol Cytogenet, 2014. 7(1): p. 58.

[36] Zitzmann, M., et al., Male smokers have a decreased success rate for in vitro fertilization and intracytoplasmic sperm injection. Fertil Steril, 2003. 79 Suppl 3: p. 1550-4. 
[37] Eisenberg, M.L. and L.I. Lipshultz, Varicocele-induced infertility: Newer insights into its pathophysiology. Indian J Urol, 2011. 27(1): p. 58-64.

[38] Santos, E.P., et al., Impact of spontaneous smoking cessation on sperm quality: case report. Andrologia, 2011. 43(6): p. 431-5.

[39] Gades, N.M., et al., Association between smoking and erectile dysfunction: a population-based study. Am J Epidemiol, 2005. 161(4): p. 346-51.

[40] McVary, K.T., et al., Smoking and erectile dysfunction: evidence based analysis. J Urol, 2001. 166(5): p. 1624-32.

[41] Edirisinghe, I., et al., Cigarette-smoke-induced oxidative/nitrosative stress impairs VEGF-and fluid-shear-stress-mediated signaling in endothelial cells. Antioxid Redox Signal, 2010. 12(12): p. 1355-69.

[42] Park, K., et al., Risk factors in predicting a poor response to sildenafil citrate in elderly men with erectile dysfunction. BJU Int, 2005. 95(3): p. 366-70.

[43] Vidal Moreno, J.F., B. Moreno Pardo, and J.F. Jimenez Cruz, [Assessment of tobacco impact on penile vascularization with echo-Doppler and intracavernous injection]. Actas Urol Esp, 1996. 20(4): p. 365-71.

[44] Harte, C.B. and C.M. Meston, Association between smoking cessation and sexual health in men. BJU Int, 2012. 109(6): p. 888-96.

[45] Liu, C.C., et al., The impact of cigarette smoking, alcohol drinking and betel quid chewing on the risk of calcium urolithiasis. Ann Epidemiol, 2009. 19(8): p. 539-45.

[46] Hamano, S., et al., Kidney stone disease and risk factors for coronary heart disease. Int J Urol, 2005. 12(10): p. 859-63.

[47] Scott, R., et al., The importance of cadmium as a factor in calcified upper urinary tract stone disease--a prospective 7-year study. Br J Urol, 1982. 54(6): p. 584-9.

[48] Fazlioglu, A., et al., The effect of smoking on spontaneous passage of distal ureteral stones. BMC Urol, 2014. 14: p. 27.

[49] Koskimaki, J., et al., Association of smoking with lower urinary tract symptoms. J Urol, 1998. 159(5): p. 1580-2.

[50] Nuotio, M., et al., Association of smoking with urgency in older people. Eur Urol, 2001. 40(2): p. 206-12.

[51] Bump, R.C. and D.K. McClish, Cigarette smoking and urinary incontinence in women. Am J Obstet Gynecol, 1992. 167(5): p. 1213-8.

[52] Kokanali, M.K., et al., Risk factors for mesh erosion after vaginal sling procedures for urinary incontinence. Eur J Obstet Gynecol Reprod Biol, 2014. 177: p. 146-50.

[53] Hahn, R.G., Smoking increases the risk of large scale fluid absorption during transurethral prostatic resection. J Urol, 2001. 166(1): p. 162-5.

[54] Breyer, B.N., et al., Multivariate analysis of risk factors for long-term urethroplasty outcome. J Urol, 2010. 183(2): p. 613-7.

[55] Chuahirun, T. and D.E. Wesson, Cigarette smoking predicts faster progression of type 2 established diabetic nephropathy despite ACE inhibition. Am J Kidney Dis, 2002. 39(2): p. 37682.

[56] Omoloja, A., et al., Secondhand smoke exposure is associated with proteinuria in children with chronic kidney disease. Pediatr Nephrol, 2013. 28(8): p. 1243-51.

[57] Nourbala, M.H., et al., Impact of cigarette smoking on kidney transplant recipients: a systematic review. Iran J Kidney Dis, 2011. 5(3): p. 141-8.

[58] Sung, R.S., et al., Excess risk of renal allograft loss associated with cigarette smoking. Transplantation, 2001. 71(12): p. 1752-7.

[59] Heldt, J., et al., Donor Smoking Negatively Affects Donor and Recipient Renal Function following Living Donor Nephrectomy. Adv Urol, 2011. 2011: p. 929263.

[60] Corbett, C., M.J. Armstrong, and J. Neuberger, Tobacco smoking and solid organ transplantation. Transplantation, 2012. 94(10): p. 979-87. 
[61] Bjurlin, M.A., et al., Ethnicity and smoking status are associated with awareness of smoking related genitourinary diseases. J Urol, 2012. 188(3): p. 724-8.

[62] Bjurlin, M.A., S.M. Goble, and C.M. Hollowell, Smoking cessation assistance for patients with bladder cancer: a national survey of American urologists. J Urol, 2010. 184(5): p. 1901-6.

[63] Johnson, B., et al., Evaluating the effectiveness of a smoking warning label on raising patient awareness of smoking and bladder cancer. J Urol, 2013. 190(2): p. 475-9.

[64] Bjurlin, M.A., et al., Brief smoking cessation intervention: a prospective trial in the urology setting. J Urol, 2013. 189(5): p. 1843-9.

[65] Jacob, P., 3rd, et al., Anabasine and anatabine as biomarkers for tobacco use during nicotine replacement therapy. Cancer Epidemiol Biomarkers Prev, 2002. 11(12): p. 1668-73.

[66] McLaughlin, J.C., et al., Preoperative and intraoperative risk factors associated with 30-day morbidity following urological surgery: the National Surgical Quality Improvement Program. J Urol, 2006. 176(5): p. 2179-86; discussion 2186.

[67] Wallner, L.P., et al., Risk factors for prolonged length of stay after urologic surgery: the National Surgical Quality Improvement Program. J Am Coll Surg, 2008. 207(6): p. 904-13.

\section{AUTHOR's BIOGRAPHY}

John Maa MD, FACS, Marin General Hospital, 5 Bon Air Road, \#101, Larkspur, CA 94939, And UC Office of the President, Tobacco Related Disease Research Program, 300 Lakeshore Drive $6^{\text {th }}$ Floor, Oakland CA 94612. 